\title{
Amyloid $\beta$ and tau pathology in brains of aged pinniped species (sea lion, seal, and walrus)
}

\author{
Yuta Takaichi ${ }^{1}$, James K. Chambers ${ }^{1 *} \mathbb{0}$, Kei Takahashi ${ }^{1}$, Yoshiyuki Soeda ${ }^{2}$, Riki Koike ${ }^{2}$, Etsuko Katsumata ${ }^{3}$, \\ Chiaki Kita ${ }^{4}$, Fuko Matsuda ${ }^{5}$ Makoto Haritani ${ }^{6}$, Akihiko Takashima ${ }^{2}$, Hiroyuki Nakayama ${ }^{1}$ and Kazuyuki Uchida ${ }^{1}$
}

\begin{abstract}
Alzheimer's disease (AD) is characterized by the accumulation of amyloid- $\beta(A \beta)$ as senile plaques and cerebral amyloid angiopathy, and hyperphosphorylated tau (hp-tau) as neurofibrillary tangles in the brain. The AD-related pathology has been reported in several non-human animals, and most animals develop only the A $\beta$ or tau pathology. We herein describe the $A \beta$ and hp-tau pathology in the brains of aged pinniped species (seal, sea lion, and walrus). Molecular analyses revealed that the sequence of pinniped $A \beta$ was identical to that of human $A \beta$. Histopathological examinations detected argyrophilic plaques composed of $A \beta$ associated with dystrophic neurites in the cerebral cortex of aged pinnipeds. Astrogliosis and microglial infiltration were identified around $A \beta$ plaques. $A \beta$ deposits were observed in the blood vessel walls of the meninges and cerebrum. Pinniped tau protein was physiologically subjected to alternative splicing at exons 2, 3, and 10, and presented as five isoforms: two 3-repeat tau isoforms (1N3R, 2N3R) and three 4-repeat tau isoforms (ON4R, 1N4R, 2N4R); ON3R tau isoform was absent. Histopathological examinations revealed argyrophilic fibrillar aggregates composed of hp-tau in the neuronal somata and neurites of aged pinniped brains. Few hp-tau aggregates were found in oligodendrocytes and microglia. Biochemically, hp-tau of the 3-repeat and 4-repeat isoforms was detected in brain sarkosyl-insoluble fractions. A $\beta$ and hp-tau both predominantly accumulated in the neocortex, particularly the frontal cortex. Furthermore, the activation of GSK-3 $\beta$ was detected within cells containing hp-tau aggregates, and activated GSK-3 $\beta$ was strongly expressed in cases with severe hp-tau pathologies. The present results suggest that, in association with $A \beta$ deposition, the activation of GSK-3ß contributes to hp-tau accumulation in pinniped brains. Here, we report that pinniped species naturally accumulate $A \beta$ and tau with aging, similar to the human AD pathology.
\end{abstract}

Keywords: Alzheimer's disease, Amyloid $\beta$, GSK-3ß, Tau, Pinniped, Neurodegeneration

\section{Background}

Alzheimer's disease (AD) is the most prevalent agerelated neurodegenerative disorder and is characterized by the pathological aggregation of the amyloid- $\beta(A \beta)$ and hyperphosphorylated tau (hp-tau) proteins in the form of senile plaques (SPs) and neurofibrillary tangles

\footnotetext{
*Correspondence: achamber@mail.ecc.u-tokyo.ac.jp

${ }^{1}$ Laboratory of Veterinary Pathology, Graduate School of Agricultural and Life Sciences, The University of Tokyo, Tokyo 113-8657, Japan

Full list of author information is available at the end of the article
}

(NFTs), respectively [1]. The accumulation of $A \beta$ in the blood vessels of the brain, a condition known as cerebral amyloid angiopathy (CAA) [2], is also detected in more than $80 \%$ of patients with $\mathrm{AD}$ [3]. Humans appear to be uniquely susceptible to $\mathrm{AD}$, potentially due to genetic differences, changes in cerebral structures and functions during evolution, and an increased lifespan [4-7]. In the "amyloid hypothesis", the most acknowledged explanation for the pathogenesis of $\mathrm{AD}$, the age-dependent accumulation of fibrillar insoluble $A \beta$ peptides in the brain is considered to be the central and triggering event in $\mathrm{AD}$

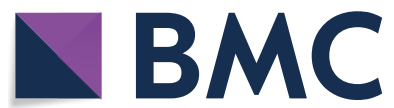

(c) The Author(s) 2021. This article is licensed under a Creative Commons Attribution 4.0 International License, which permits use, sharing, adaptation, distribution and reproduction in any medium or format, as long as you give appropriate credit to the original author(s) and the source, provide a link to the Creative Commons licence, and indicate if changes were made. The images or other third party material in this article are included in the article's Creative Commons licence, unless indicated otherwise in a credit line to the material. If material is not included in the article's Creative Commons licence and your intended use is not permitted by statutory regulation or exceeds the permitted use, you will need to obtain permission directly from the copyright holder. To view a copy of this licence, visit http://creativeco mmons.org/licenses/by/4.0/. The Creative Commons Public Domain Dedication waiver (http://creativecommons.org/publicdomain/ zero/1.0/) applies to the data made available in this article, unless otherwise stated in a credit line to the data. 
pathology [8]. Based on this hypothesis, various transgenic mouse models that produce human $A \beta$ beyond physiological levels have been generated and exhibit the massive formation of SPs. However, they fail to develop NFTs and neuronal loss unless mutant tau is simultaneously introduced [9].

While AD appears to be a human-specific disease, agedependent SP formation has been reported in several non-human primates, including chimpanzees [10], orangutans [11], and gorillas [12]. The concomitant pathology with the formation of a small amount of NFTs was found in chimpanzees [13, 14] and rhesus macaques [15], while the oligodendroglial tau pathology was also detected in cynomolgus monkeys [16]. Therefore, an AD-like pathology may occur during aging in primates. In contrast, non-primate animals, particularly Carnivora species, have exhibited species-specific patterns of $A \beta$ and hp-tau accumulation (Table 1). In the suborder Caniformia, aged dogs $[17,18]$ and bears [19] developed SPs in their brains, but not NFTs, even in the oldest subjects, except for one wolverine [20]. On the other hand, Feliformia species, such as cats [21, 22], leopard cats [23], and cheetahs [24], exhibit NFTs without SP formation, although small granular deposits of $A \beta$ were detected in the cerebral cortex.

Pinnipeds are semiaquatic carnivorans that spend most of their lives in water, and use coastal terrestrial environments and ice packs to breed, molt, and rest. They are currently classified into three families: Phocidae (seals), Otariidae (fur seals and sea lions), and Odobenidae (walruses). They may have evolved within a group of arctoid carnivores in the Pacific Ocean 27 million years ago. Although their origin is a matter of discussion, they are currently regarded as a monophyletic group [25]. One case study confirmed SP formation and CAA, but not NFTs, in the brain of a 30-year-old California sea lion
(Zalophus californianus) [26]. In the present study, we performed comprehensive genetic, biochemical, and pathological analyses of the brains of young to old pinniped species (aged between 0 and 35 years). The results obtained showed that aged pinniped species exhibited the concomitant accumulation of $A \beta$ and hp-tau in their brains. Pinniped brains produced $A \beta$ with an amino acid sequence that was identical to that of humans, developed SPs in the cerebral cortex, and exhibited CAA. Their brains expressed five isoforms of tau (1N3R, 2N3R, 0N4R, 1N4R, and 2N4R), and formed NFTs in the neuronal somata and neurites of the cerebral cortex. We herein report our results on the $A \beta$ and tau pathology in the brains of pinniped species and discuss the relationship between the accumulation of $A \beta$ and hp-tau in consideration of comparative biology.

\section{Methods \\ Animals}

Ten pinniped brain tissues were examined (Table 2). All samples were obtained through routine necropsies performed at the Laboratory of Veterinary Pathology, the University of Tokyo. All procedures were conducted according to the institutional regulations for animal research. One hemisphere of the brain was fixed in $10 \%$ neutral-buffered formalin, and the other was coronally sectioned and frozen at $-80^{\circ} \mathrm{C}$ until used.

\section{Histopathology}

Formalin-fixed tissues were embedded in paraffin wax and cut into 4- or 8- $\mu \mathrm{m}$-thick serial sections. Deparaffinized sections were then stained using hematoxylin and eosin (HE), periodic acid-methenamine silver (PAM), Congo red, Thioflavin-S, and the Gallyas-Braak methods.

Table 1 Occurrence of senile plaques (SP) and neurofibrillary tangles (NFT) in carnivora species

\begin{tabular}{|c|c|c|c|c|c|c|}
\hline Suborder & Infraorder & Superfamily & Family & Species & SP & NFT \\
\hline \multirow[t]{8}{*}{ Caniformia } & Cynoidea & & Canidae & Domestic dog (Canis lupus familiaris) & Yes & No \\
\hline & Arctoidea & Pinnipedia & Phocidae & Harbor seal (Phoca largha, Phoca vitulina) & Yes & Yes \\
\hline & & & Otariidae & Northern sea lion (Eumetopias jubatus) & Yes & Yes \\
\hline & & & & California sea lion (Zalophus californianus) & Yes & Yes \\
\hline & & & & Australian sea lion (Neophoca cinerea) & Yes & Yes \\
\hline & & & Odobenidae & Walrus (Odobenus rosmarus) & Yes & Yes \\
\hline & & Musteloidea & Mustelidae & Wolverine (Gulo gulo) & Yes & Yes \\
\hline & & Ursoidea & Ursidae & American black bear (Ursus americanus) & Yes & No \\
\hline \multirow[t]{3}{*}{ Feliformia } & & Feloidea & Felidae & Domestic cat (Felis silvestris catus) & No & Yes \\
\hline & & & & Leopard cat (Prionailurus bengalensis) & No & Yes \\
\hline & & & & Cheetah (Acinonyx jubatus) & No & Yes \\
\hline
\end{tabular}




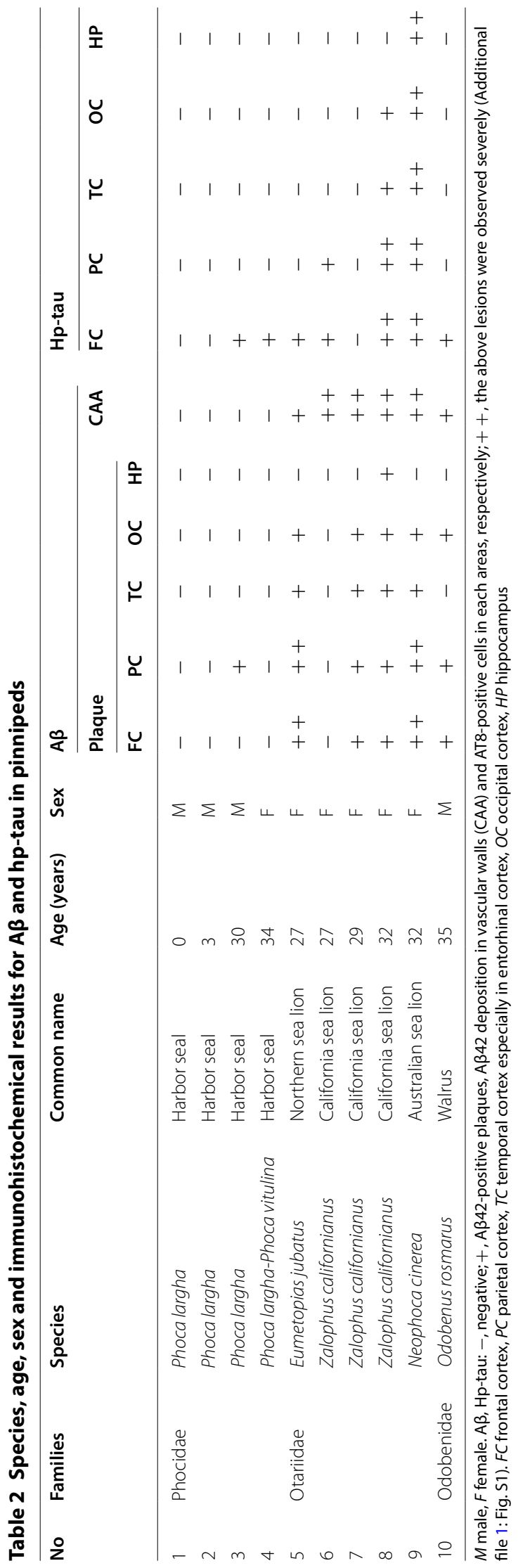




\section{Immunohistochemistry}

Consecutive sections were stained using an immunoenzyme technique. After deparaffinization and rehydration, antigen retrieval was performed via heating or with formic acid (for $A \beta$ ). To deactivate endogenous peroxidase, sections were immersed in $1 \%$ hydrogen peroxide in methanol for $5 \mathrm{~min}$. To avoid non-specific binding of the antibody, sections were immersed in $8 \%$ skim milk in Tris-buffered saline (TBS). The following primary antibodies were used: mouse anti-A $\beta 42$ (clone 12F4, 1:1000, Millipore, Temecula, CA), rabbit anti-A $\beta 40$ (clone 11A5B10, 1:1000, Millipore), rabbit anti-A $\beta N 1$ (1:100, IBL, Gunma, Japan), rabbit anti-A $\beta p N 3$ (1:100, IBL), rabbit anti-apolipoprotein (Apo) E (1:100, IBL), mouse anti3-repeat-tau (clone 8E6/C11, 1:100, Millipore), mouse anti-4-repeat-tau (clone 1E1/A6, 1:300, Millipore), mouse anti-hp-tau (Ser202/Thr205) (clone AT8, 1:500, Thermo Scientific, Rockford, IL), mouse anti-hp-tau (Ser212/Thr214) (clone AT100, 1:500, Thermo Scientific), mouse anti-phosphorylated- $\alpha$-synuclein (Ser129) (clone 81A, 1:150, Abcam, Cambridge, UK), rabbit antiTDP-43 (1:300, ProteinTech, Rosemont, IL), rabbit antiGSK-3 $\beta$ (clone 27C10, 1:100, Cell Signaling Technology, Beverly, MA) and rabbit anti-phosphorylated-GSK-3 $\beta$ (Tyr216) (p-GSK-3 $\beta$ (Tyr216)) (1:100, Novus Biologicals, Centennial, $\mathrm{CO})$. After an incubation with each primary antibody at $4^{\circ} \mathrm{C}$ overnight, immunolabeled antigens were visualized using the Dako EnVision + System (Dako, Glostrup, Denmark) with 0.02\% 3'3-diaminobenzidine plus $0.01 \%$ hydrogen peroxide as a chromogen.

\section{Double-labeling immunofluorescence}

To detect the spatial and temporal distribution of $A \beta$ and hp-tau, we performed double immunohistochemistry and double-labeling immunofluorescence. In double immunohistochemistry, sections were initially incubated with the mouse anti-A $\beta 42$ (clone $12 \mathrm{~F} 4,1: 1000$ ) or rabbit anti-A $\beta 42$ (1:300, DAKO) antibody and then visualized with $0.02 \% 3^{\prime} 3$-diaminobenzidine plus $0.01 \%$ hydrogen peroxide as a chromogen. Slides were incubated with the rabbit anti-GFAP (1:800, DAKO), rabbit anti-Iba-1 (1:200, WAKO, Osaka, Japan), or mouse anti-synaptophysin (clone DAK-SYNAP, 1:500, DAKO) antibody, visualized with new fuchsin (Nichirei Corporation, Tokyo, Japan) as a chromogen, and then counterstained with hematoxylin. In double-labeling immunofluorescence, after an incubation with each of the primary antibodies at $4{ }^{\circ} \mathrm{C}$ overnight, sections were washed with TBS, incubated with the corresponding secondary antibodies at room temperature for $1 \mathrm{~h}$, and then mounted with Vectashield (H-1500, Vector Laboratories, Burlingame, CA). The following primary antibodies were used: mouse anti-hp-tau (Ser202/Thr205) (clone AT8, 1:100), rabbit anti-p-GSK-3 $\beta$ (Tyr216) (1:100), rabbit anti-MAP2 (1:100, Millipore), rabbit anti-GFAP (1:400), rabbit antiOlig2 (1:100, Millipore), and rabbit anti-Iba-1 (1:150). The following secondary antibodies were used: Alexa Fluor 594-conjugated goat anti-mouse IgG (1:100, Invitrogen, Eugene, OR), Alexa Fluor 488-conjugated goat anti-rabbit IgG (1:100, Life Technologies, Eugene, OR), Alexa Fluor 594-conjugated goat anti-rabbit IgG (1:100, Life Technologies), and Alexa Fluor 488-conjugated goat anti-mouse IgG (1:100, Invitrogen). Fluorescent reaction products were optimally visualized using an argon ion laser under a Carl Zeiss LSM700 Confocal Laser Scanning Microscope (Carl Zeiss, Tokyo, Japan).

\section{Protein extraction}

Tissue samples from the forebrain were homogenized in 7.5 volumes of TBS buffer containing $50 \mathrm{mM}$ Tris $(\mathrm{pH}$ 7.4), 150 mM NaCl, 1 mM EGTA, 1 mM EDTA, $10.5 \mu \mathrm{m}$ leupeptin, $307 \mathrm{nM}$ aprotinin, $7.3 \mu \mathrm{m}$ pepstatin, $1 \mu \mathrm{M}$ okadic acid, $1 \mathrm{mM}$ glycerophosphate, $1 \mathrm{mM} \mathrm{Na}_{3} \mathrm{VO}_{4}$, and $1 \mathrm{mM} \mathrm{NaF}$. After centrifugation at 23,000 rpm at $4{ }^{\circ} \mathrm{C}$ for $15 \mathrm{~min}$, supernatants were collected as TBS-soluble fractions. Pellets were rehomogenized in 7.5 volumes of sucrose buffer containing $0.32 \mathrm{M}$ sucrose, $10 \mathrm{mM}$ Tris/ $\mathrm{HCl}$ (pH 7.4), 1 mM EGTA, $0.8 \mathrm{M} \mathrm{NaCl}, 10.5 \mu \mathrm{m}$ leupeptin, $307 \mathrm{nM}$ aprotinin, $7.3 \mu \mathrm{m}$ pepstatin, $1 \mu \mathrm{M}$ okadic acid, $1 \mathrm{mM}$ glycerophosphate, $1 \mathrm{mM} \mathrm{Na}_{3} \mathrm{VO}_{4}$, and $1 \mathrm{mM}$ $\mathrm{NaF}$ and then centrifuged as described above. Supernatants were collected and incubated with sarkosyl (Wako, $1 \%$ final concentration) at $37^{\circ} \mathrm{C}$ for $1 \mathrm{~h}$, followed by centrifugation at $60,000 \mathrm{rpm}$ at $4{ }^{\circ} \mathrm{C}$ for $60 \mathrm{~min}$, and then collected as sarkosyl-soluble fractions. Pellets were resuspended in TBS buffer to a volume equivalent to the wet weight of the original tissue (sarkosyl-insoluble fractions). In the dephosphorylation treatment, TBS-soluble fractions were incubated in alkaline phosphatase buffer containing $50 \mathrm{mM}$ Tris- $\mathrm{HCl}$ pH 8.0, $100 \mathrm{mM} \mathrm{KCl,} 1 \mathrm{mM}$ $\mathrm{MgSO}_{4}, 50 \%$ glycerol, and 1-3 $\mathrm{U}$ bacterial alkaline phosphatase (TaKaRa, Shiga, Japan) at $37^{\circ} \mathrm{C}$ for $3 \mathrm{~h}$.

\section{Western blotting}

Protein samples were dissolved in Laemmli Sample Buffer (SB), which included 2-mercaptoethanol, and were then boiled for $10 \mathrm{~min}$. Proteins dissolved in Laemmli SB were separated using a 10\% polyacrylamide gel (ATTO, Tokyo, Japan) and then transferred to a nitrocellulose membrane with a pore size of $0.20 \mu \mathrm{m}$ (GE Healthcare Bio-Sciences AB, Uppsala, Sweden). Non-specific binding was blocked by a treatment with $1 \%$ skim milk for 60 min (Nacalai Tesque, Kyoto, Japan). Membranes were probed with the following antibodies at $4{ }^{\circ} \mathrm{C}$ overnight: rabbit anti-tau (1:1000, produced by A. Takashima's laboratory), mouse anti-3-repeat-tau (clone 8E6/C11, 1:500), 
mouse anti-4-repeat-tau (clone 1E1/A6, 1:500), mouse anti-hp-tau (Ser202/Thr205) (clone AT8, 1:500), mouse anti-hp-tau (Ser212/Thr214) (clone AT100, 1:500), rabbit anti-GSK-3 $\beta$ (clone 27C10, 1:100), rabbit anti-p-GSK-3 $\beta$ (Tyr216) (1:500), and horseradish peroxidase (HRP)-conjugated mouse anti- $\beta$-actin (clone 8H10D10, 1:5000, Cell Signaling Technology). After washing the membranes with TBS containing Tween 20, a HRP-conjugated sheep anti-rabbit IgG antibody (1:5000, GE Healthcare UK, Little Chalfont, UK) or HRP-conjugated sheep anti-mouse IgG antibody (1:5000 GE Healthcare UK) was applied. Blots were developed using the ECL Select Western Blotting Detection Reagent (GE Healthcare Bio-Sciences AB). Immunoreactive bands were detected using the ChemiDoc XRS + System (Bio-Rad Laboratories, Hercules, CA).

\section{Electron microscopy}

Formalin-fixed brain samples were washed with phosphate-buffered saline ( $\mathrm{pH} 7.4)$ and then post-fixed in $1 \%$ osmium tetroxide. Samples were dehydrated and embedded in resin Luveak-812 (Nacalai Tesque). Uranyl acetate and lead nitrate-stained ultrathin sections were then examined with a transmission electron microscope (JEM-1400Plus, JEOL, Tokyo, Japan). For negative-stain electron microscopy, samples of sarkosyl insoluble-fractions were stained with uranyl acetate, and examined with the transmission electron microscope.

\section{RT-PCR analysis}

In the molecular analysis of the APP and MAPT genes, total RNA was extracted from frozen brain tissue using the RNeasy Mini Kit (Qiagen, Valencia, CA). Extracted total RNA was used to synthesize cDNA (Prime Script RT-PCR kit, TaKaRa). Purified cDNA was used for subsequent PCR. Gene-specific primers, listed in Additional file 1: Table S1, were used. PCR was performed as follows: 35 cycles at $98{ }^{\circ} \mathrm{C}$ for $10 \mathrm{~s}$ and $60{ }^{\circ} \mathrm{C}$ for $30 \mathrm{~s}$. PCR products were electrophoresed on an agarose gel and analyzed using a ChemiDocTM imaging system (Bio-Rad Laboratories). Target amplification products were extracted from gel bands using a SV Gel and PCR Clean-Up System
(Promega, Madison, WI) and subjected to a sequence analysis (FASMAC, Toyama, Japan). Multiple sequence alignment was performed using CLUSTALW (Kyoto University, Kyoto, Japan).

\section{Results \\ Amyloid $\beta$ sequence analysis}

The sequence analysis of the $A P P$ transcripts obtained from five pinniped species (case No. 4, 5, 8, 9, and 10) revealed that their $A \beta$ domains had similar nucleic acid sequences. In comparisons with the Phocidae APP sequence (case No. 4), the same nucleic acid substitutions in the $A \beta$ domain were found in Otariidae (case No. 5, 8 , and 9) and Odobenidae (case No. 10) species (Additional file 1: Fig. S2a). In spite of this nucleic acid substitution in the $A \beta$ domains, the $A \beta$ amino acid sequence was conserved among pinniped species (Additional file 1: Fig. S2b). The multiple sequence alignment of pinniped $\mathrm{A} \beta$ with human, chimpanzee, dog, cat, and murine $\mathrm{A} \beta$ showed that the amino acid sequence of pinniped $A \beta$ was homologous to that of humans, chimpanzees, and dogs, which formed age-associated amyloid plaques in their brains $[1,10,17,18]$, and different from that of cats and rodents, which did not spontaneously form amyloid plaques [27, 28] (Fig. 1).

\section{Amyloid plaque formation}

Histopathological examinations revealed two types of amyloid plaques in the parenchyma of the cerebral cortex of aged pinniped brains (Fig. 2a). The first type was small round plaques with a PAM-positive central core (Fig. 2b), while the second type was observed as large diffuse plaques without a distinct core (Fig. 2c). These plaques were also visualized using Gallyas-Braak silver staining (Fig. 2d). In an immunohistochemical analysis with anti-A $\beta$ antibodies, numerous $A \beta 42$-positive (Fig. 2e, f) and a few A 340 -positive deposits (Fig. 2g) were detected in the cerebral cortex of aged pinniped brains. A small proportion of these deposits were positive for $A \beta N 1$ (Fig. $2 \mathrm{~h}$ ), which recognizes the $\mathrm{N}$ terminus of $\mathrm{A} \beta$, and $\mathrm{A} \beta \mathrm{pN} 3$ (Fig. 2i), which recognizes $\mathrm{N}$-terminally truncated $A \beta$. In the cerebral cortex, $A \beta p N 3$-positive

\section{Pinniped \\ 5'-DAEFRHDSGYEVHHQKLVFFAEDVGSNKGA I I GLMVGGVV I A-3' Human 5'-DAEFRHDSGYEVHHQKLVFFAEDVGSNKGA I I GLMVGGVV I A-3' Chimpanzee 5'-DAEFRHDSGYEVHHQKLVFFAEDVGSNKGA I I GLMVGGVV I A-3' Dog 5'-DAEFRHDSGYEVHHQKLVFFAEDVGSNKGA I I GLMVGGVV I A-3' Cat 5'-DAEFRHESGYEVHHQKLVFFAEDVGSNKGA I I GLMVGGVV I A-3' Mouse 5'-DAEFGHDSGEEVRHQKLVFFAEDVGSNKGA I I GLMVGGVV I A-3'}

Fig. 1 Amino acid sequence analysis of the APP gene containing the A $\beta$ region. Multiple A protein alignments among different mammalian orthologs 


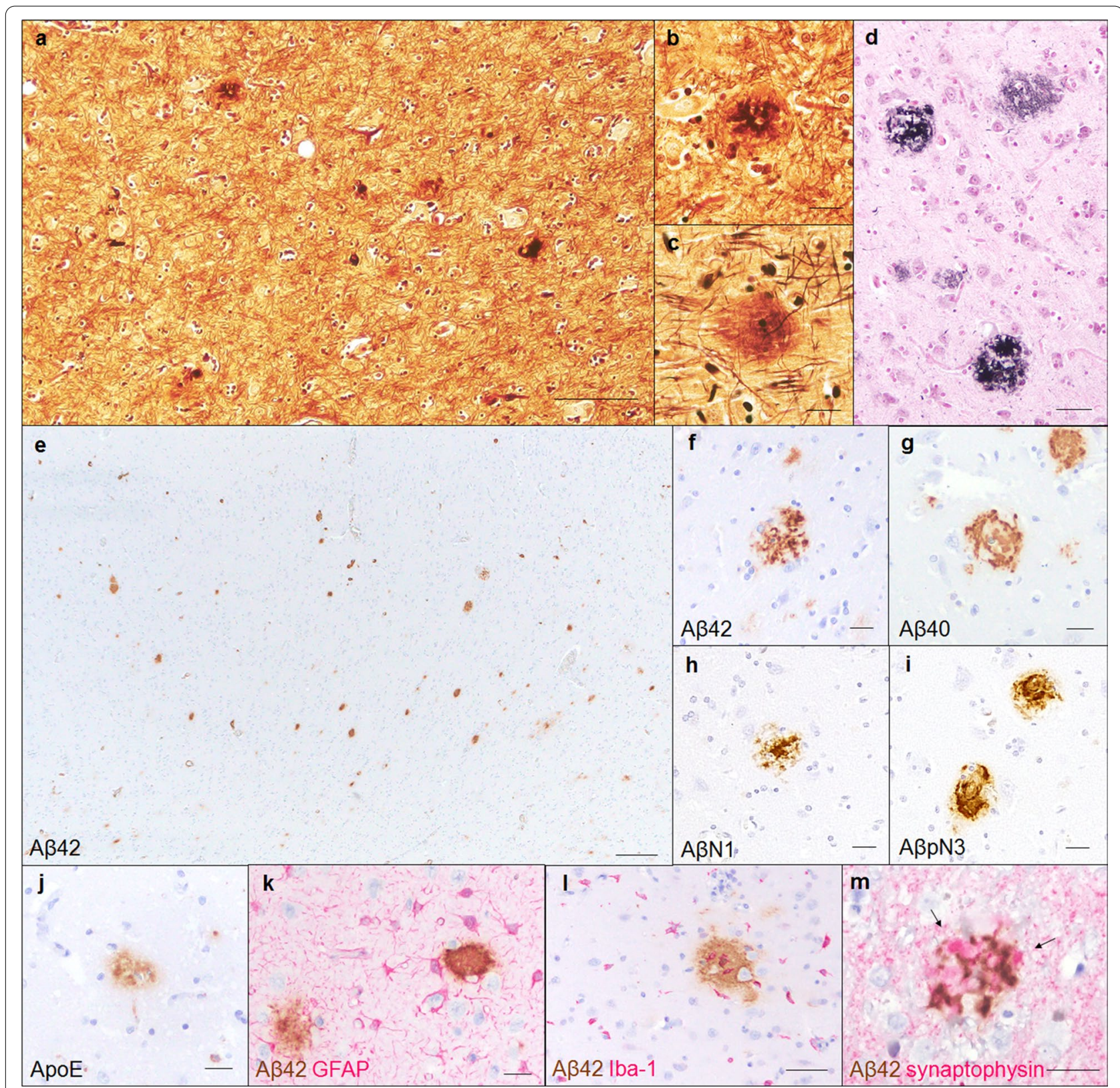

Fig. 2 Amyloid plaques in the cerebral cortex of aged pinnipeds (case No. 9). PAM-positive amyloid plaques were observed in the parenchyma of the cerebral cortex (a). Amyloid plaques were morphologically classified into two types, small round plaques (b) and large plaques (c), and were positive for Gallyas-Braak silver staining (d). Immunohistochemically, amyloid plaques were positive for $A \beta 42(\mathbf{e}, \mathbf{f}), A \beta 40(\mathbf{g}), A \beta N 1$ (h), A $3 p N 3(\mathbf{i})$, and ApoE (j). The moderate infiltration of GFAP-positive astrocytes ( $\mathbf{k}$ ) and Iba-1-positive microglia (I) was observed around and on A 342 -positive amyloid plaques. Swollen dystrophic neurites (arrows) were observed and accompanied by Aß42-positive amyloid plaques (m). Reactions to A 42 $(\mathbf{k}, \mathbf{I}, \mathbf{m})$ are shown in brown, and those to GFAP $(\mathbf{k})$, Iba-1 (I), and synaptophysin $(\mathbf{m})$ in red. Scale bars: $100 \mu \mathrm{m}(\mathbf{a}) ; 20 \mu \mathrm{m}(\mathbf{b}-\mathbf{d}, \mathbf{f}-\mathbf{k}, \mathbf{m}) ; 50 \mu \mathrm{m}(\mathbf{I}) ;$ $200 \mu \mathrm{m}(\mathbf{e})$

deposits were more common than $\mathrm{A} \beta \mathrm{N} 1$-positive deposits. Furthermore, the ApoE protein colocalized with $A \beta$ deposits (Fig. 2j). To elucidate the relationship between aging and amyloid plaque formation, we examined the distribution of $A \beta$ deposits at various ages. In an immunohistochemical analysis with the anti-A $\beta 42$ antibody, although we did not find any A 342 -positive deposits in infantile (case No. 1, 0 years old) or juvenile brains (case No. 2, 3 years old), A $\beta 42$-positive deposits were detected in the brains of aged pinnipeds (case No. 3-10, 27 to 35 years old) (6/8 cases, Table 2). A $\beta 42$-positive deposits were found in the cerebral cortex of the frontal lobe 
(5/8 cases), parietal lobe (6/8 cases), temporal lobe $(4 / 8$ cases), and occipital lobe (5/8 cases) and also in the hippocampus (only in case No. 8), but not in the cerebral white matter, cerebellum, or brain stem (Table 2). To evaluate peri-plaque neuroinflammation and synaptic changes in aged pinniped brains, we performed double immunohistochemistry. GFAP and Iba-1 staining showed an increased number and size of astrocytes and microglia around Aß42-positive deposits (Fig. 2k, 1). Synaptophysin staining revealed enlarged presynapses surrounding A 342 -positive deposits, which are considered as small round plaques, showing peri-plaque dystrophies associated with amyloid plaque formation (Fig. $2 \mathrm{~m}$ ).

\section{Vascular $A \beta$ deposits}

Histopathologically, eosinophilic deposits were found within the arterial walls of the meninges and the small arterial and capillary walls of the cerebral cortex of aged pinniped brains, which were positive for Congo red staining with apple-green birefringence under polarized light (Fig. 3a, b). In the immunohistochemical analysis with anti-A $\beta$ antibodies, these deposits were positive for $A \beta 40$ (Fig. 3c), $A \beta 42$ (Fig. 3d), $A \beta p N 3$ (Fig. 3e), and $A \beta N 1$ (Fig. 3f). The vascular deposition of $A \beta 42$ and A 340 was similar, with A 342 deposits being located in the vessel wall and $A \beta 40$ deposits surrounding the blood vessels and spreading into the neuropil (Fig. 3c, d). A $\beta$ N1-positive vessels were more commonly observed than $\mathrm{A} \beta \mathrm{pN} 3$-positive vessels. Furthermore, the ApoE protein colocalized with $A \beta$ deposits in the blood vessels (Fig. $3 \mathrm{~g}$ ). In an immunohistochemical analysis with the anti-A $\beta 42$ antibody, vascular $A \beta$ deposits were found in the cerebral cortex and meninges of most aged pinnipeds (6/8 cases), and four aged pinnipeds (case No. 6-9) showed severe $A \beta$ deposition in the blood vessel walls. A 342 -positive vascular deposits were found in the cerebral cortex of the frontal lobe $(6 / 6$ cases $)$, parietal lobe (6/6 cases), temporal lobe (4/6 cases), and occipital lobe (6/6 cases) and also in the hippocampus (5/6 cases), but not in the cerebellum or brain stem (Table 2).

\section{Expression pattern of tau isoforms}

To confirm the splicing patterns of the pinniped tau protein, $M A P T$ transcripts obtained from five pinniped brains (case No. 4, 5, 8, 9, and 10) were examined. RTPCR with primer pair 2 detected three distinct bands of approximately 450,550, and $650 \mathrm{bp}$, and a sequence analysis revealed that all PCR products contained exons 1, 4, and 5 of the $M A P T$ gene, and exon 2 was also contained in the 550- and 650-bp bands and exon 3 in the 650-bp

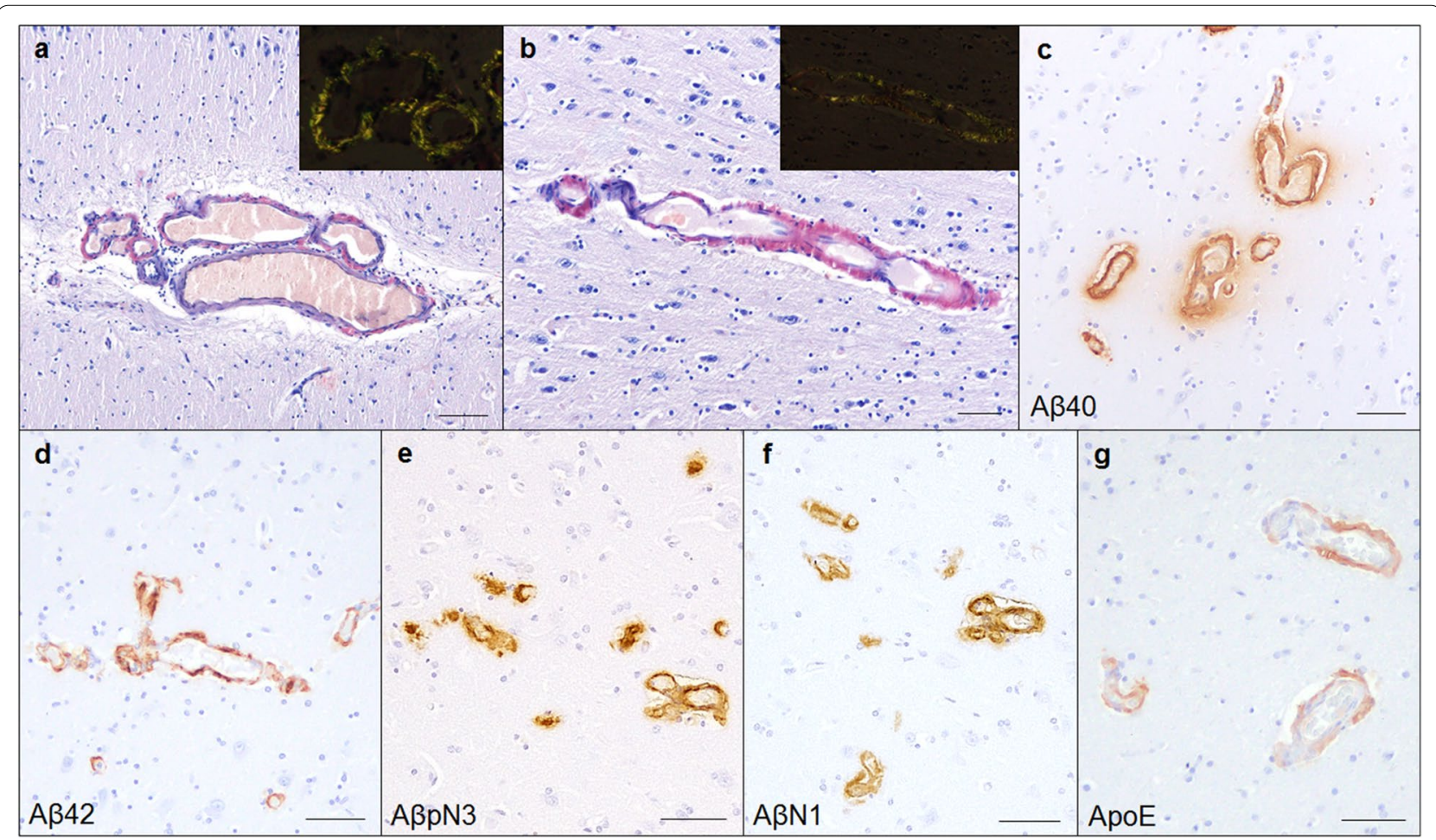

Fig. 3 CAA in aged pinniped brains (case No. 9). Congo red-positive amyloid deposition was observed on the blood vessels of the meninges (a) and cerebral cortex (b). These deposits showed typical apple-green birefringence under polarized light (inset). Immunohistochemically, amyloid

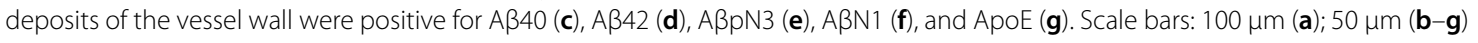


band (Fig. 4a, b). RT-PCR with primer pair 3 detected two distinct bands of 350 and $450 \mathrm{bp}$, and a sequence analysis revealed that all PCR products contained exons $2,4,5$, and 7 of the MAPT gene, and exon 3 was also contained in the 450-bp band (Additional file 1: Fig. S3a, b). RT-PCR with primer pair 4 detected a distinct band at $500 \mathrm{bp}$, and a sequence analysis revealed that the PCR product contained exons 5, 7, and 9 of the MAPT gene (Additional file 1: Fig. S3c, d). RT-PCR with primer pair 5 detected two distinct bands of 150 and $250 \mathrm{bp}$, and a sequence analysis revealed that all PCR products contained exons 9 and 11 of the MAPT gene, and exon 10 was also contained in the 250-bp band (Fig. 4c, d). RTPCR with primer pair 6 detected a distinct band of $450 \mathrm{bp}$, and a sequence analysis revealed that all PCR products contained exons 11,12 , and 13 of the MAPT gene (Additional file 1: Fig. S3e, f). Exons 1, 4, 5, 7, 9, 11, 12 , and 13 of the MAPT gene were constitutive exons, and exons 2, 3, 4a, 6, 8, and 10 were subjected to alternative splicing. Exons 4a, 6, and 8 were not present in pinniped brains. Western blotting of TBS-soluble fractions from infantile and aged pinniped cerebrums revealed the expression of five isoforms of tau (1N3R, 2N3R, 0N4R, 1N4R, and 2N4R) (Fig. 5, Additional file 1: Fig. S4).

\section{NFT formation}

We examined the tau pathology in aged pinniped brains using Gallyas-Braak silver staining, and confirmed silver-positive fibrillar aggregates in the neuronal somata and neurites of cerebral cortex pyramidal cell layers (layers III and V) (Fig. 6a, b). Thioflavin-S staining detected fibrillar aggregates

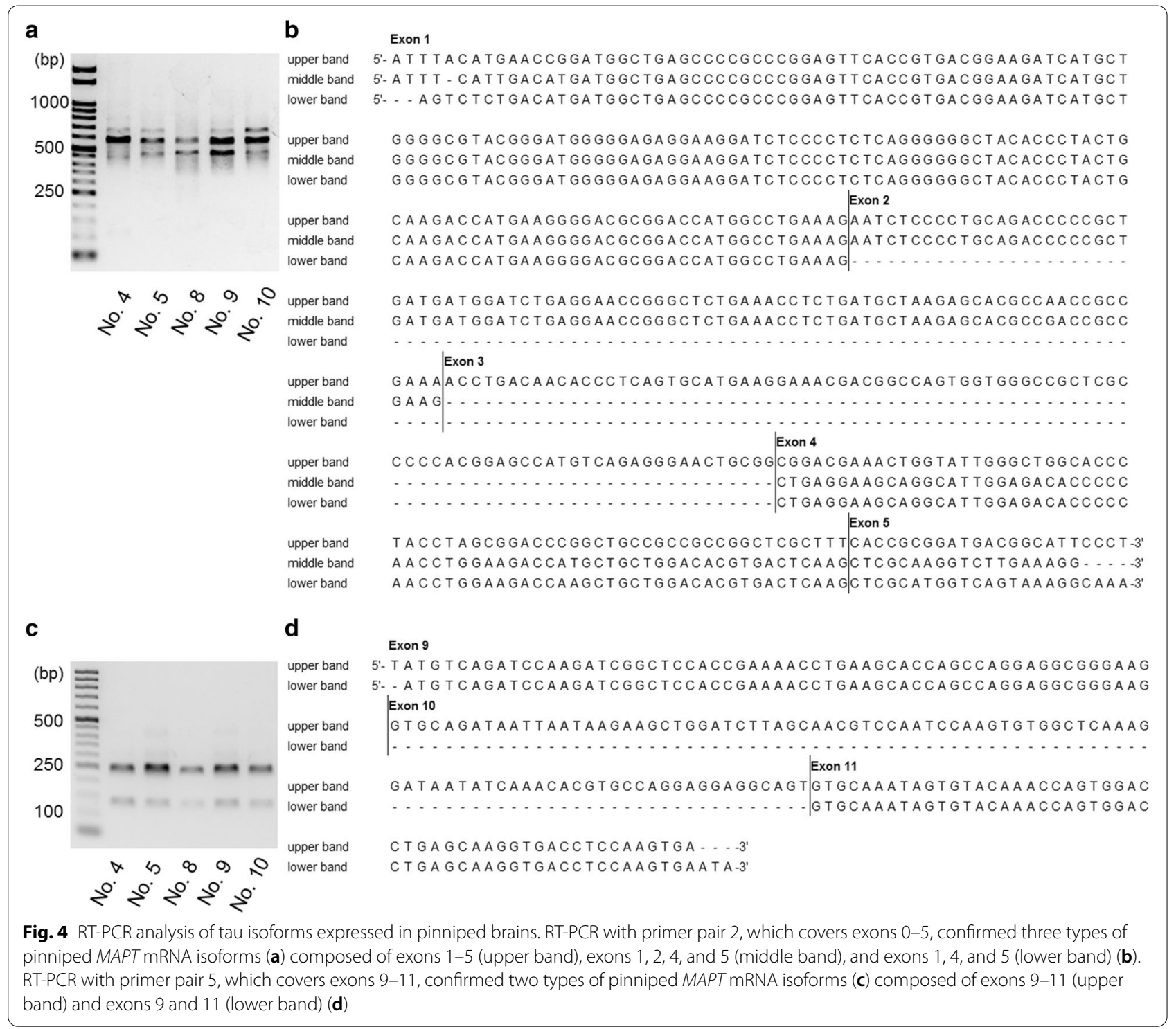




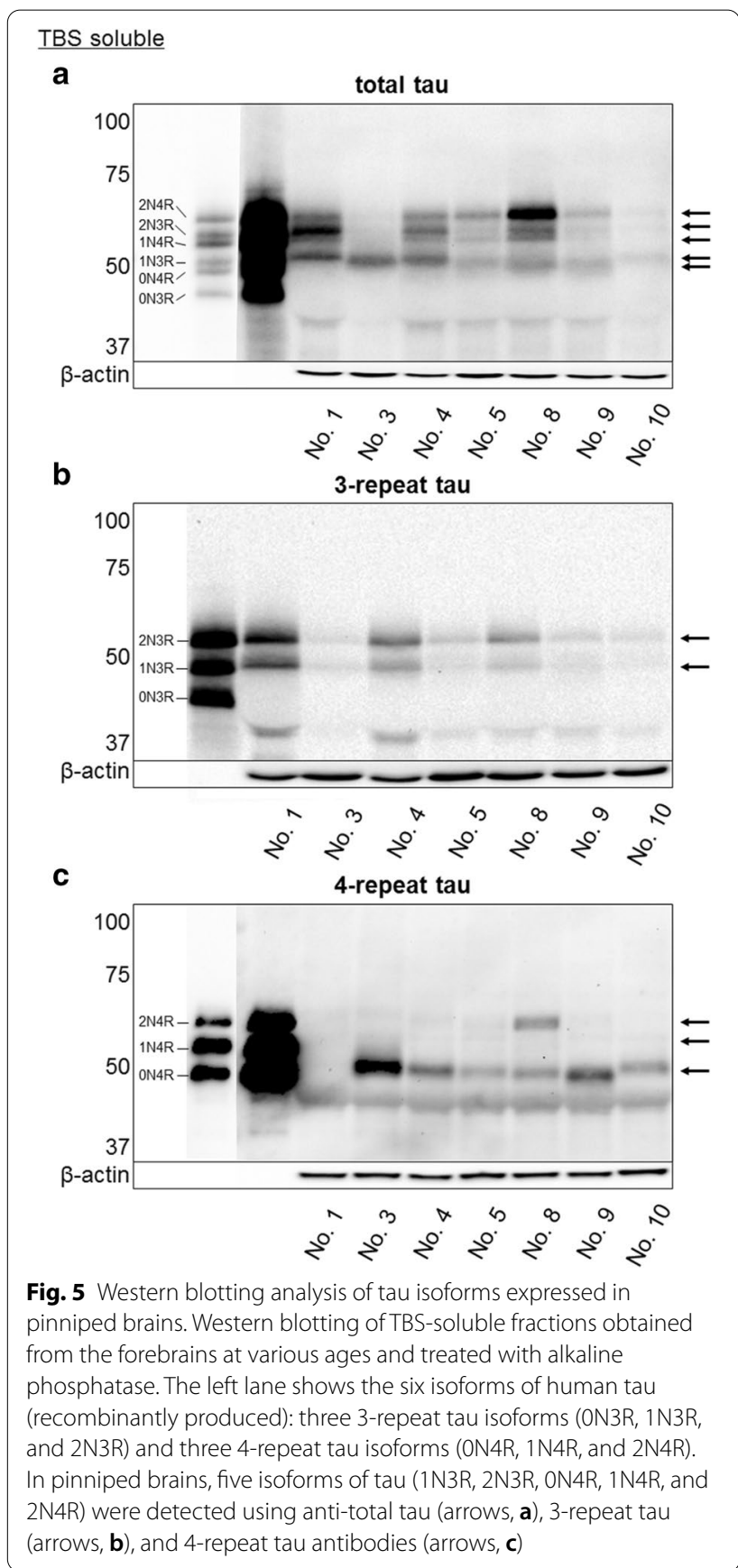

in the neurites (Fig. 6c). An immunohistochemical analysis with anti-hp-tau antibodies showed that aggregates were positive for AT8 (Fig. 6d, e), which recognized tau phosphorylated at Ser202 and Thr205, and AT100 (Fig. 6f), which recognized tau phosphorylated at Thr212 and Ser214. Immunohistochemistry for GFAP and Iba-1 showed an increased number and size of astrocytes and microglial infiltration in the cerebral cortex of aged pinnipeds (Fig. 6g, h). In electron microscopy, bundles of filaments with a diameter of approximately $10 \mathrm{~nm}$ were observed in the neuronal somata and neurites (Fig. 6i). Numerous straight filaments, having a diameter of approximately $10 \mathrm{~nm}$, were detected in sarkosyl-insoluble fractions (Fig. 6j). A double-labeling immunofluorescence analysis revealed that hp-tau aggregates were mostly present in MAP2-positive neuronal cells (Fig. 6k), but not in GFAP-positive astrocytes (Fig. 6l). Additionally, hptau aggregates were detected in a few Olig2-positive oligodendrocytes (Fig. $6 \mathrm{~m}$ ) and Iba-1-positive microglia (Fig. 6n). In an immunohistochemical analysis with the anti-AT8 antibody, the majority of pinnipeds older than 27 years old displayed hp-tau aggregates (7/8 cases, Table 2$)$. These aggregates were found in the cerebral cortex, but not in the cerebral white matter, cerebellum, or brain stem. AT8-positive aggregates were observed in the cortex of the frontal lobe $(7 / 8$ cases), parietal lobe (3/8 cases), temporal lobe $(2 / 8$ cases), and occipital lobe (2/8 cases), and only case No. 9 developed hp-tau aggregates in the hippocampus (Table 2). There was no $\alpha$-synuclein or TDP-43 pathology in the brains of any pinnipeds (data not shown). The Western blotting analysis using anti-tau antibodies indicated that sarkosyl-insoluble fractions prepared from the frontal lobe cortex tissues of aged pinnipeds contained abundant tau (Fig. 7a). These insoluble tau species, which showed a smear profile in Western blots, consisted of both the $3 R$ and $4 R$ tau isoforms, which were phosphorylated (Fig. 7b-d).

\section{GSK-3 $\beta$ activation associated with NFT formation}

We examined the activation of GSK-3 $\beta$, a major kinase for tau phosphorylation, in pinniped brains. An immunohistochemical analysis revealed uniform GSK-3 $\beta$ expression in the neuronal cytoplasm of all cases (Fig. 8a). In addition, GSK-3 $\beta$-positive grains were found in aged cases (Fig. 8a). Furthermore, aged pinnipeds showed p-GSK-3 $\beta$ (Tyr216)-positive grains, which are an active form of GSK-3 $\beta$, in the neuronal somata of the cerebral cortex (Fig. 8b). A doublelabeling immunofluorescence analysis revealed that hp-tau aggregates and p-GSK-3 $\beta$ (Tyr216)-positive grains were detected within the same cells (Fig. 8c). A Western blotting analysis revealed that the expression levels of p-GSK-3 $\beta$ (Tyr216) were higher in case No. 8 and 9, in which severe hp-tau accumulation was confirmed immunohistochemically, than in other cases (Fig. 8d, e). 


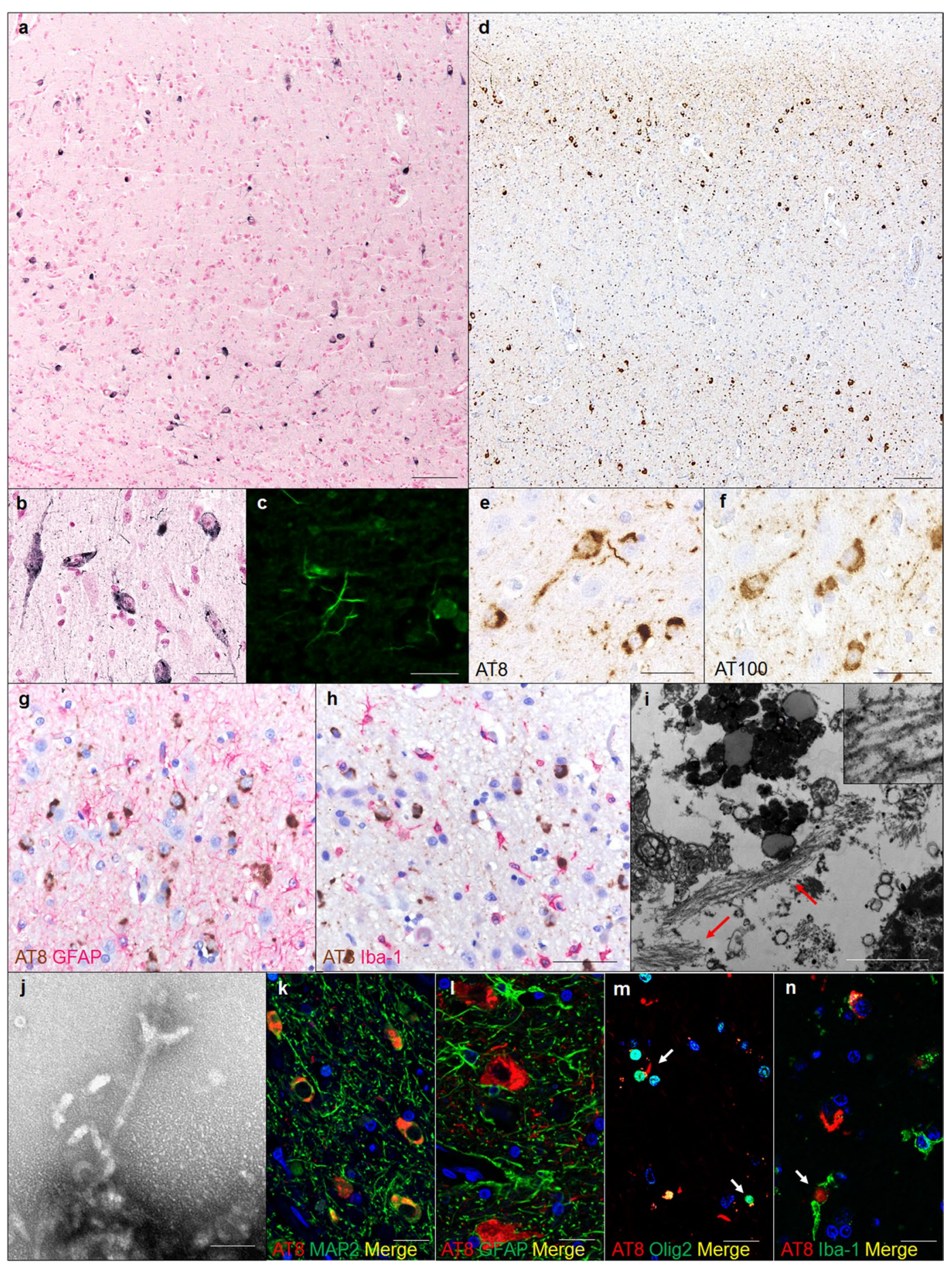

Fig. 6 NFTs in the cerebral cortex of aged pinnipeds (case No. 9). Gallyas-Braak staining-positive argyrophilic aggregates were observed in the neuronal somata and neurites in cerebral cortex pyramidal cell layers $(\mathbf{a}, \mathbf{b})$. Thioflavin-S staining-positive neurites were observed in cerebral cortex (c). Immunohistochemically, these aggregates were positive for AT8 $(\mathbf{d}, \mathbf{e})$ and AT100 (f). GFAP-positive astrocytes (g) and Iba-1-positive microglia (h) were observed in the cerebral cortex. Reactions to AT8 $(\mathbf{g}, \mathbf{h})$ are shown in brown, and those to GFAP (g) and Iba-1 (h) in red. Transmission electron microscopy detected bundles of filaments in neuronal soma of aged pinnipeds (arrows, i). Sarkosyl-insoluble filaments with a diameter of approximately $10 \mathrm{~nm}$ in the cerebral cortex of aged pinnipeds (j). AT8-positive hp-tau aggregates were observed in MAP2-positive neurons (k), but not in GFAP-positive astrocytes (I). Some AT8-positive hp-tau aggregates were observed in Olig2-positive oligodendrocytes (arrows, $\mathbf{m}$ ) and

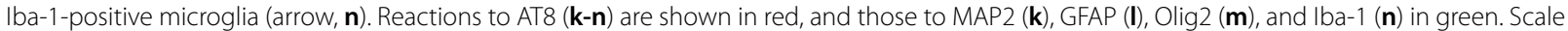
bars: $100 \mu \mathrm{m}(\mathbf{a}, \mathbf{d}) ; 50 \mu \mathrm{m}(\mathbf{b}, \mathbf{e}-\mathbf{h}) ; 2 \mu \mathrm{m}(\mathbf{i}) ; 50 \mathrm{~nm}(\mathbf{j}) ; 10 \mu \mathrm{m}(\mathbf{c}, \mathbf{k}-\mathbf{n})$ 


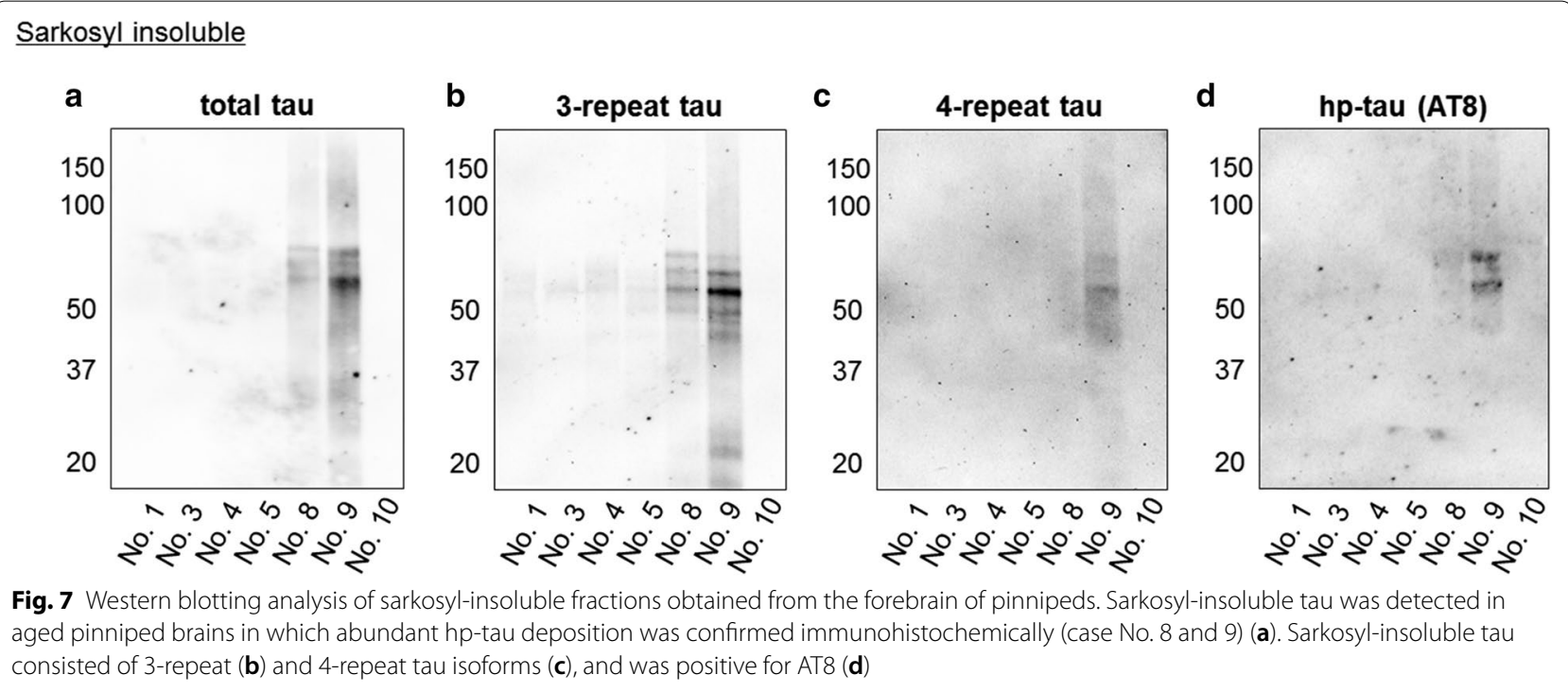

\section{Discussion}

Animals that spontaneously develop SPs in aged brains, such as monkeys and dogs, share the same $A \beta$ peptide amino acid sequence as humans [29]. In contrast, SP formation has never been demonstrated in non-transgenic wild-type rodents, such as rats and mice, or cats. Rodent A $\beta$ displays three amino acid differences in its N-terminal region from human $A \beta[28]$, and one amino acid located in the $\mathrm{N}$-terminal region of cat $\mathrm{A} \beta$ protein differed from that of human $A \beta$ [27]. In the present study, we detected amyloid plaque formation in aged pinniped brains, and their $A \beta$ peptide amino acid sequence was the same as that of human $A \beta$, providing support for spontaneous amyloid plaque formation specifically developing in animals that express the human type $A \beta$. In humans, amyloid plaques are generally categorized as SP (neuritic plaque) and diffuse plaques [1]. In the present study, we detected two types of amyloid plaques, small round plaques and large plaques. The small round plaques of pinnipeds were similar to human SPs because of the presence of a PAM-positive central core of $A \beta$ and dystrophic neurites surrounding plaques; however, the large plaques lacking a central core were similar to human diffuse plaques. Previous studies confirmed that human neurotoxic amyloid plaques were predominantly composed of $A \beta 40$ and $A \beta 42$, and $A \beta 42$ was more abundant in plaques than $A \beta 40$ because of its higher rate of fibrillization and insolubility as well as its ability to form insoluble clumps of oligomers [30]. The N-terminal subtype of $A \beta$ peptides also affects their aggregability, and, thus, plaque formation. $A \beta$ truncated at $\mathrm{N}$-terminal position 3 is catalyzed by glutaminyl cyclase, which produces abundant $\mathrm{A} \beta \mathrm{pN} 3$ in the $\mathrm{AD}$ brain, but not in the normal aging brain [31], and $\mathrm{A} \beta \mathrm{pN} 3$ is more depositable than $A \beta N 1$ [32]. Immunohistochemistry for $A \beta$ revealed that $A \beta 42$ more prominently accumulated than $A \beta 40$ in the parenchyma of pinniped brains, and some amyloid plaques were positive for $A \beta p N 3$, suggesting the presence of $A \beta$ species with a higher aggregation capability and neurotoxicity in pinniped brains. Though the $A \beta 42$ deposition was severer in the sea lion and walrus brains than seal brains, the distribution pattern was comparable among three pinniped species. $A \beta$ plaques were the most abundant in the frontal, parietal, and temporal neocortices and some were detected in the hippocampus, whereas none were found in the brain stem; this progression aligns with the Thal $A \beta$ phases of deposition in humans [33]. Previous studies revealed that the accumulation of $A \beta$ induced a neuroinflammatory response. The infiltration of microglia and reactive astrocytes is commonly observed in the periphery of amyloid plaques [34], and the barrier formed by astrocytes and microglia around plaques was described as a reactive glial net [35]. In the present study, activated astrocytes and microglia were found in some amyloid plaques (cored plaques), but not in diffuse plaques. In addition to amyloid plaques, we also detected the severe deposition of $A \beta$ in the walls of blood vessels in the cerebral cortex and meninges of aged pinnipeds. Previous human studies reported that CAA was present in more than $80 \%$ of patients with $\mathrm{AD}$ and up to $40 \%$ of cognitively unimpaired elderly individuals [3]. In contrast to amyloid plaques, $A \beta 40$ was more abundant in CAA than $A \beta 42$ [36], and amyloid deposition progressed in a regional pattern, with the greatest accumulation being observed in the occipital cortex followed by the prefrontal cortex and hippocampus. The severity of 

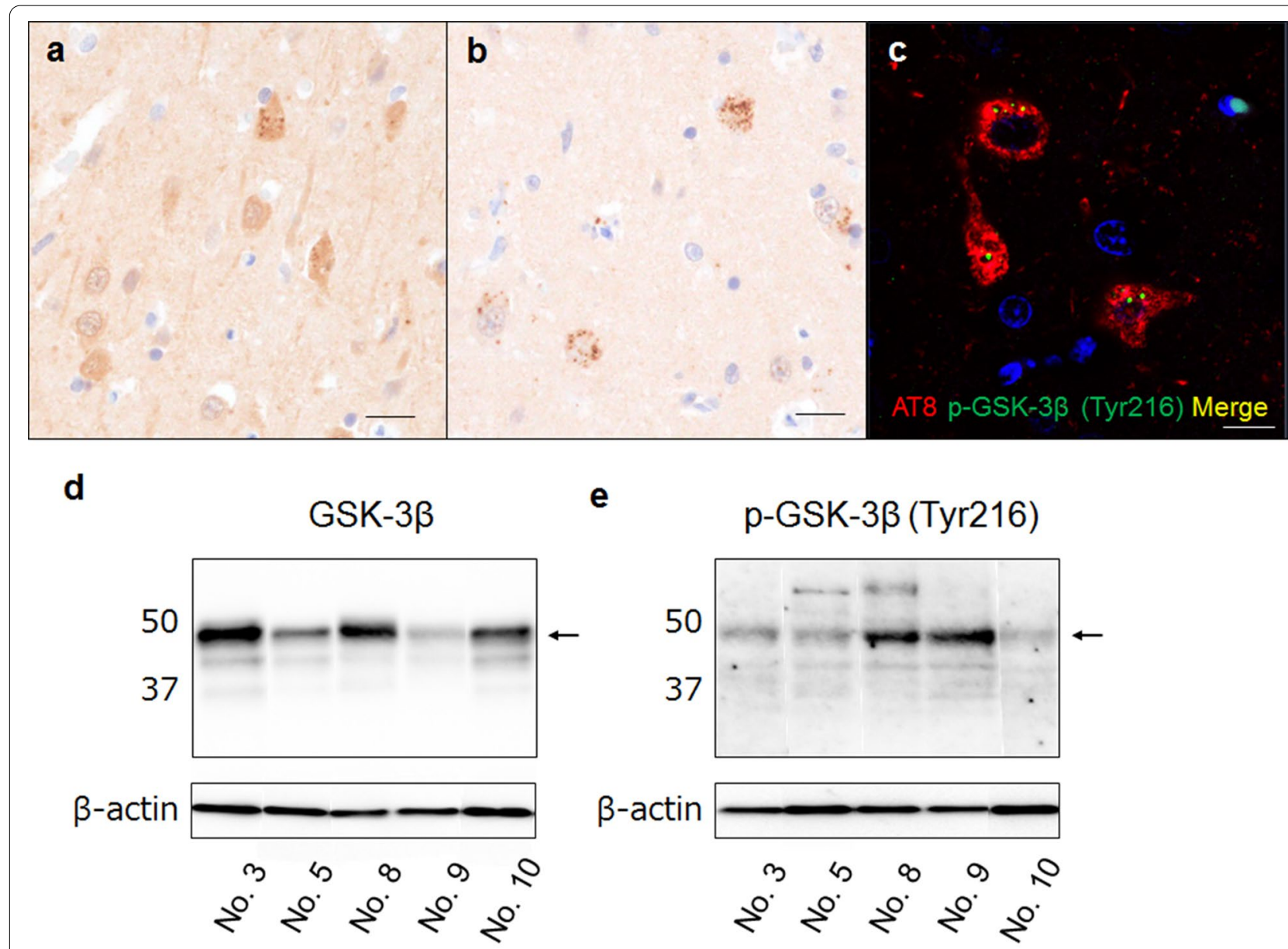

e $\quad$-GSK-3 $\beta($ Tyr216)

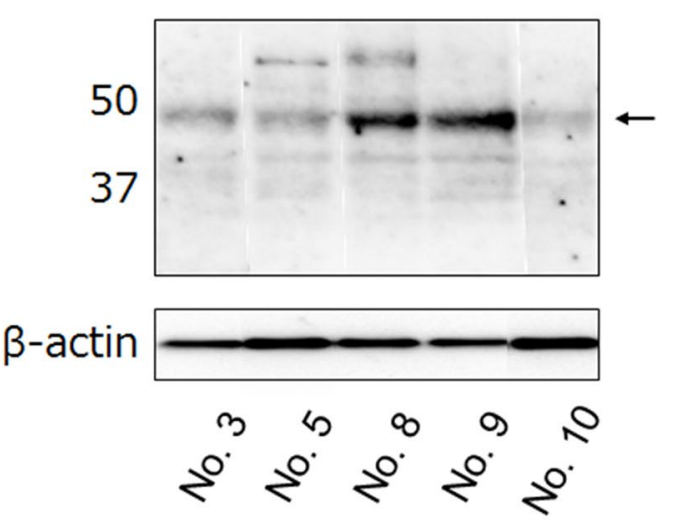

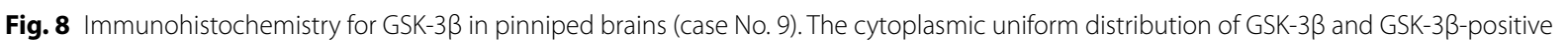
grains was found in the neuronal somata of aged pinnipeds (a). P-GSK-3 $\beta$ (Tyr216)-positive cells were found in aged pinniped brains (b). Double-labeling immunofluorescence in the cerebral cortex of aged pinnipeds revealed that p-GSK-3 $\beta$ (Tyr216)-positive grains were localized in

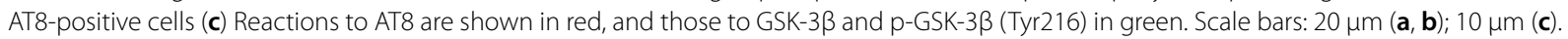
Western blotting analysis of GSK-3 $\beta$ in TBS-soluble fractions from the forebrain of pinnipeds. A distinct band of GSK-3 $\beta$ with a molecular weight of $46 \mathrm{kDa}$ was detected in pinniped brains (arrow, d). A stronger band of p-GSK-3 $\beta$ (Tyr216) was detected in case No. 8 and 9, in which severe hp-tau accumulation was confirmed immunohistochemically, than in other cases (arrow, e)

occipital CAA positively correlated with the severity of $\mathrm{AD}$ [37]. In the present study, we detected the vascular deposition of $A \beta$ in $6 / 8$ cases of aged pinnipeds. Its severity was the highest in the frontal, parietal, and occipital regions, followed by the temporal region and hippocampus. These results suggest that pinniped brains frequently develop CAA with aging, with similar progression to that in humans. Although the numbers of $A \beta 40$ - and $A \beta 42-$ positive blood vessels appeared to be similar, $A \beta 40$ positive dispersed aggregates were also detected at the neuropil around blood vessels in aged pinnipeds, and this distribution pattern has been reported in human patients with dysphoric angiopathy [38]. Based on the perivascular deposition of $A \beta 40$, we speculate that $A \beta 40$ accumulates slightly more than $A \beta 42$ in the vessel walls and is a main component of pinniped CAA.
The activity of the tau protein is influenced by a number of functional tubulin-binding domains and depends on the splicing of exon 10, which directly influences whether the tau protein expressed will contain three (3R) or four (4R) domains, termed incomplete tandem repeats. The existence of two other alternatively spliced exons (exons 2 and 3 ) increases the maximal number of tau isoforms in the central nervous system to six [39]. The expression patterns of $3 \mathrm{R}$ and $4 \mathrm{R}$ tau differ among animal species and developmental stages. All six isoforms of tau (0N3R, 1N3R, 2N3R, 0N4R, 1N4R, and $2 \mathrm{~N} 4 \mathrm{R}$ ) are expressed in adult human and cat brains, while 4 isoforms are expressed in adult dog $(2 \mathrm{~N} 3 \mathrm{R}$, $0 \mathrm{~N} 4 \mathrm{R}, 1 \mathrm{~N} 4 \mathrm{R}$, and $2 \mathrm{~N} 4 \mathrm{R})$, pig, and bovine brains (1N3R, $2 \mathrm{~N} 3 \mathrm{R}, 1 \mathrm{~N} 4 \mathrm{R}$, and $2 \mathrm{~N} 4 \mathrm{R})$. Adult rodent brains only express $4 \mathrm{R}$ tau isoforms (0N4R, 1N4R, and 2N4R) [40]. 
Mammalian species that spontaneously develop NFT, such as humans, chimpanzees [14], and cats [17, 22], have been reported to express six tau isoforms in their brains, and the expression of all tau isoforms appears to be a prerequisite for NFT formation. In the present study, we confirmed the alternative splicing of exons 2 , 3 , and 10 of the $M A P T$ gene and the expression of five isoforms of tau in pinniped brains (1N3R, 2N3R, 0N4R, $1 N 4 R$, and 2N4R), suggesting that it is sufficient to form NFTs in the absence of 0N3R tau expression in pinniped brains. Tau proteins were hyperphosphorylated and predominantly aggregated in the neurons of the cerebral cortex pyramidal cell layers (layers III and V). These structures were argyrophilic with Gallyas-Braak staining, ultrastructually filamentous, and composed of both $3 \mathrm{R}$ and $4 \mathrm{R}$ tau isoforms detected in sarkosylinsoluble fractions. This cytopathology matches NFTs in AD patients [34]; however, the distribution of the tau pathology markedly differed from that in AD patients. Recent studies proposed a seeding hypothesis in which small amounts of misfolded proteins act as seeds that initiate the recruitment of their soluble counterparts into fibrils and the cell-to-cell transmission of protein aggregates, and the spread of NFTs closely correlates with disease progression; therefore, the distribution of NFTs is important for identifying the disease stages of sporadic AD [41]. According to Braak staging, tau inclusions develop in the locus coeruleus as well as in the transentorhinal and entorhinal regions (Stages I and II). This is followed by their presence in the hippocampal formation and some parts of the neocortex (Stages III and IV), followed by large parts of the neocortex (Stages V and VI) [42]. In the present study, though NFTs were more detectable in the sea lion brains than seal and walrus brains, the distribution pattern was comparable among three pinniped species. Pinnipeds did not develop NFTs in the subcortical nuclei, such as the locus coeruleus and magnocellular nuclei. NFTs were predominantly detected within the frontal neocortex in the majority of the aged cases examined (7/8 cases) and in the parietal ( $3 / 8$ cases) and occipital neocortices ( $2 / 8$ cases). In severe cases (case No. 8 and 9), the hippocampus and entorhinal cortex were affected as well as entire regions of the cerebral cortex (frontal, parietal, and occipital cortices). These results suggest that tauopathic changes in the aged pinniped brain are characterized by the AD-like formation of NFTs in the neocortex, which originally occurs in the cortex of the frontal lobe and spreads to related cortical regions. Since $A \beta$ plaques were the most abundant in the frontal, parietal, and temporal neocortices, and relatively fewer in the hippocampus, the regional distribution of tau was similar to that of $A \beta$. Therefore, we speculate that these distribution patterns suggest a relationship between $A \beta$ deposition and hp-tau accumulation in pinniped brains. In the Wnt/GSK-3 $\beta$ hypothesis of $A D$ $[43,44], A \beta$ has been suggested to inhibit Wnt signaling and induce the activation of GSK-3 $\beta$, known as Tau kinase I. The activation of GSK-3 $\beta$ induces an increase in the tau pathology associated with decreases and deficits in neurons [45]. We detected the activation of GSK-3 $\beta$ within cells in which hp-tau accumulated in the neocortex of aged pinniped brains, and the amounts of activated GSK- $3 \beta$ were higher in cases with abundant NFTs. Therefore, we speculate that A $\beta$-induced GSK-3 $\beta$ activation contributes to the formation of NFTs in the neocortex of pinniped and human brains.

Carnivora species have been described with characteristic AD-like pathologies, such as the formation of SPs in aged dogs and bears and NFTs in aged cats. In the present study, we confirmed that aged pinniped species developed SPs and NFTs in the cerebral cortex, and this is the first comprehensive study to report a spontaneous full AD pathology (SP and NFT) in non-primate animals. The simultaneous neocortical distribution of SPs and NFTs and the activation of GSK- $3 \beta$ suggest interactions between $A \beta$ and hp-tau associated with changes in kinase activities in the neocortex of pinniped brains. Although the precise mechanisms underlying pathological differences among animal species currently remain unclear, a basic biochemical difference may be one reason because the $A \beta$ sequence is highly conserved in animals with the spontaneous formation of SPs, such as humans, monkeys, dogs, and pinnipeds, but not mice or cats, while NFTs were detected in animals expressing more than four tau isoforms in their brains, such as humans, monkeys, cats, and pinnipeds, but not mice or dogs (Table 1). Based on these histopathological and biochemical features of pinniped brains, a comparative study among Carnivora species may provide insights into other mechanisms of AD, and may be useful for investigating the pathogenesis of and possible treatments for this disease.

\section{Supplementary information}

Supplementary information accompanies this paper at https://doi. org/10.1186/s40478-020-01104-3.

Additional file 1: Table S1. Primer sequences and expected PCR product sizes (in base pair) used to analyze the expression of APP and tau in pinniped brains. Fig. S1. Immunohistochemistry for Aß42 and AT8 in pinniped brains. Fig. S2. Nucleic acid and amino acid sequence analyses of the APP gene containing the $A \beta$ region. Fig. S3. RT-PCR analysis of tau isoforms expressed in pinniped brains. Fig. S4. A Western blotting analysis of tau isoforms in pinniped brains (longer exposure time of Figure 5C).

\section{Acknowledgements}

We thank Mr. K Otani, R Saito and K Kojima for their excellent technical assistance. 


\section{Author contributions}

$\mathrm{YT}$ conducted the experiments, analyzed the results, and wrote the manuscript. KU, HN, AT, MH, EK, FM, CK, EK, RK, YS, KT and JKC conducted experiments and critically revised the manuscript. All authors read and approved the final manuscript.

\section{Funding}

The work was supported by a grant-in-aid from Japanese Society for the Promotion of Science $(18 \mathrm{H} 02338,19 J 22779)$.

\section{Availability of data and materials}

The datasets during and/or analyzed during the current study available from the corresponding author on reasonable request.

\section{Competing interests}

The authors have no duality or conflicts of interest to declare.

\section{Author details}

${ }^{1}$ Laboratory of Veterinary Pathology, Graduate School of Agricultural and Life Sciences, The University of Tokyo, Tokyo 113-8657, Japan. ${ }^{2}$ Department of Life Science, Faculty of Science, Gakushuin University, Tokyo, Japan. ${ }^{3}$ Kamogawa Seaworld, Chiba, Japan. ${ }^{4}$ Shikoku Cytopathological Laboratory, Kagawa, Japan. ${ }^{5}$ Laboratory of Theriogenology, Graduate School of Agricultural and Life Sciences, The University of Tokyo, Tokyo, Japan. ${ }^{6}$ Environmental Science for Sustainable Development, The University of Tokyo, Tokyo, Japan.

Received: 11 November 2020 Accepted: 13 December 2020 Published online: 07 January 2021

\section{References}

1. Wippold FJ 2nd, Cairns N, Vo K, Holtzman DM, Morris JC (2008) Neuropathology for the neuroradiologist: plaques and tangles. AJNR Am J Neuroradiol 29(1):18-22

2. Okazaki H, Reagan TJ, Campbell RJ (1979) Clinicopathologic studies of primary cerebral amyloid angiopathy. Mayo Clin Proc 54(1):22-31

3. Pfeifer LA, White LR, Ross GW, Petrovitch H, Launer $L J$ (2002) Cerebral amyloid angiopathy and cognitive function: the HAAS autopsy study. Neurology 58(11):1629-1634

4. Lowenstine LJ, McManamon R, Terio KA (2016) Comparative Pathology of Aging Great Apes: Bonobos, Chimpanzees, Gorillas, and Orangutans. Vet Pathol 53(2):250-276

5. Rapoport SI, Nelson PT (2011) Biomarkers and evolution in Alzheimer's disease. Prog Neurobiol 95:510-513

6. Walker LC, Jucker M (2017) The Exceptional Vulnerability of Humans to Alzheimer's Disease. Trends Mol Med 23(6):534-545

7. Youssef SA, Capucchio MT, Rofina JE, Chambers JK, Uchida K, Nakayama $\mathrm{H}$ et al (2016) Pathology of the Aging Brain in Domestic and Laboratory Animals, and Animal Models of Human Neurodegenerative Diseases. Vet Pathol 53(2):327-348

8. Hardy J, Selkoe DJ (2002) The amyloid hypothesis of Alzheimer's disease: progress and problems on the road to therapeutics. Science 297(5580):353-356

9. Duyckaerts C, Potier MC, Delatour B (2008) Alzheimer's disease models and human neuropathology: similarities and differences. Acta Neuropathol 115(1):5-38

10. Gearing M, Rebeck GW, Hyman BT, Tigges J, Mirra SS (1994) Neuropathology and apolipoprotein E profile of aged chimpanzees: implications for Alzheimer disease. Proc Natl Acad Sci USA 27; 91(20):9382-9386

11. Gearing M, Tigges J, Mori H, Mirra SS (1997) A $\beta$ deposition in the brains of aged orangutans. Neurobiol Aging 18(2):139-146

12. Perez SE, Raghanti MA, Hof PR, Kramer L, Ikonomovic MD, Lacor PN et al (2013) Alzheimer's disease pathology in the neocortex and hippocampus of the western lowland gorilla (Gorilla gorilla gorilla). J Comp Neurol 521(18):4318-4338

13. Edler MK, Sherwood CC, Meindl RS, Hopkins WD, Ely JJ, Erwin JM et al (2017) Aged chimpanzees exhibit pathologic hallmarks of Alzheimer's disease. Neurobiol Aging 59:107-120
14. Rosen RF, Farberg AS, Gearing M, Dooyema J, Long PM, Anderson DC et al (2008) Tauopathy with paired helical filaments in an aged chimpanzee. J Comp Neurol 509(3):259-270

15. Paspalas CD, Carlyle BC, Leslie S, Preuss TM, Crimins JL, Huttner AJ et al (2018) The aged rhesus macaque manifests Braak stage III/IV Alzheimer'slike pathology. Alzheimers Dement 14(5):680-691

16. Uchihara T, Endo K, Kondo H, Okabayashi S, Shimozawa N, Yasutomi Y et al (2016) Tau pathology in aged cynomolgus monkeys is progressive supranuclear palsy/corticobasal degeneration- but not Alzheimer disease-like -Ultrastructural mapping of tau by EDX. Acta Neuropathol Commun 4(1):118

17. Chambers JK, Mutsuga M, Uchida K, Nakayama H (2011) Characterization of $A \beta p N 3$ deposition in the brains of dogs of various ages and other animal species. Amyloid 18(2):63-71

18. Uchida K, Kuroki K, Yoshino T, Yamaguchi R, Tateyama S (1997) Immunohistochemical study of constituents other than $A \beta$ in canine senile plaques and cerebral amyloid angiopathy. Acta Neuropathol 93(3):277-284

19. Uchida K, Yoshino T, Yamaguchi R, Tateyama S, Kimoto Y, Nakayama H et al (1995) Senile plaques and other senile changes in the brain of an aged American black bear. Vet Pathol 32(4):412-414

20. Roertgen KE, Parisi JE, Clark HB, Barnes DL, O'Brien TD, Johnson KH (1996) $A \beta$-associated cerebral angiopathy and senile plaques with neurofibrillary tangles and cerebral hemorrhage in an aged wolverine (Gulo gulo). Neurobiol Aging 17(2):243-247

21. Chambers JK, Tokuda T, Uchida K, Ishii R, Tatebe H, Takahashi E et al (2015) The domestic cat as a natural animal model of Alzheimer's disease. Acta Neuropathol Commun 3:78

22. Fiock KL, Smith JD, Crary JF, Hefti MM (2020) $\beta$-amyloid and tau pathology in the aging feline brain. J Comp Neurol 528(1):108-113

23. Chambers JK, Uchida K, Harada T, Tsuboi M, Sato M, Kubo M et al (2012) Neurofibrillary tangles and the deposition of a beta amyloid peptide with a novel N-terminal epitope in the brains of wild Tsushima leopard cats. PLoS ONE 7(10):e46452

24. Serizawa S, Chambers JK, Une Y (2012) A 3 deposition and neurofibrillary tangles spontaneously occur in the brains of captive cheetahs (Acinonyx jubatus). Vet Pathol 49(2):304-312

25. Berta A (2009) Pinnipedia, Overview. Encyclopedia of Marine Mammals, 2nd edn. Elsevier, Academic Press, Amsterdam

26. Takahashi E, Kuribayashi H, Chambers JK, Imamura E, Une Y (2014) Senile plaques and cerebral amyloid angiopathy in an aged California sea lion (Zalophus californianus). Amyloid 21(3):211-215

27. Gotz J, Ittner LM (2008) Animal models of Alzheimer's disease and frontotemporal dementia. Nat Rev Neurosci 9:532-544

28. Jucker M, Walker LC (2011) Pathogenic protein seeding in Alzheimer's disease and other neurodegenerative disorders. Ann Neurol 70:532-540

29. Johnstone EM, Chaney MO, Norris FH, Pascual R, Little SP (1991) Conservation of the sequence of the Alzheimer's disease amyloid peptide in dog, polar bear and five other mammals by cross-species polymerase chain reaction analysis. Brain Res Mol Brain Res 10:299-305

30. Gandy $S$ (2005) The role of cerebral $A \beta$ accumulation in common forms of Alzheimer's disease. J Clin Invest 115:1121-1129

31. Schilling S, Zeitschel U, Hoffmann T, Heiser U, Francke M, Kehlen A et al (2008) Glutaminyl cyclase inhibition attenuates pyroglutamate $A \beta$ and Alzheimer's disease-like pathology. Nat Med 14(10):1106-1111

32. Saido TC, Iwatsubo T, Mann DM, Shimada H, Ihara Y, Kawashima S (1995) Dominant and differential deposition of distinct beta-amyloid peptide species, $A \beta N 3(p E)$, in senile plaques. Neuron 14(2):457-466

33. Thal DR, Rüb U, Orantes M, Braak H (2002) Phases of A $\beta$-deposition in the human brain and its relevance for the development of Alzheimer's disease. Neurology 58(12):1791-1800

34. Perl DP (2010) Neuropathology of Alzheimer's disease. Mt Sinai J Med 77(1):32-42

35. Bouvier DS, Jones EV, Quesseveur G, Davoli MA, Ferreira A, T, Quirion R, et al (2016) High resolution dissection of reactive glial nets in Alzheimer's disease. Sci Rep 6:24544

36. Gkanatsiou E, Portelius E, Toomey CE, Blennow K, Zetterberg H, Lashley T et al (2019) A distinct brain A $\beta$ signature in cerebral amyloid angiopathy compared to Alzheimer's disease. Neurosci Lett 701:125-131 
37. Attems J, Quass M, Jellinger KA, Lintner F (2007) Topographical distribution of cerebral amyloid angiopathy and its effect on cognitive decline are influenced by Alzheimer's disease pathology. J Neurol Sci 257(1-2):49-55

38. Richard E, Carrano A, Hoozemans JJ, van Horssen J, van Haastert ES, Eurelings LS et al (2010) Characteristics of dyshoric capillary cerebral amyloid angiopathy. J Neuropathol Exp Neurol 69(11):1158-1167

39. Goedert M, Spillantini MG, Jakes R, Rutherford D, Crowther RA (1989) Multiple isoforms of human microtubule-associated protein tau: sequences and localization in neurofibrillary tangles of Alzheimer's disease. Neuron 3:519-526

40. Janke C, Beck M, Stahl T, Holzer M, Brauer K, Bigl V et al (1999) Phylogenetic diversity of the expression of the microtubule-associated protein tau: implications for neurodegenerative disorders. Brain Res Mol Brain Res 68(1-2):119-128

41. Lewis J, Dickson DW (2016) Propagation of tau pathology: hypotheses, discoveries, and yet unresolved questions from experimental and human brain studies. Acta Neuropathol 131:27-48

42. Braak H, Alafuzoff I, Arzberger T, Kretzschmar H, Del Tredici K (2006) Staging of Alzheimer's disease-associated neurofibrillary pathology using paraffin sections and immunocytochemistry. Acta Neuropathol 112:389-404
43. Liu CC, Tsai CW, Deak F, Rogers J, Penuliar M, Sung YM et al (2014) Deficiency in LRP6-mediated Wnt signaling contributes to synaptic abnormalities and amyloid pathology in Alzheimer's disease. Neuron 84:63-77

44. Norwitz NG, Mota AS, Norwitz SG, Clarke K (2019) Multi-loop model of Alzheimer's disease: an integrated perspective on the Wnt/GSK3 $\beta$, a-synuclein, and type 3 diabetes hypotheses. Front Aging Neurosci 11:184

45. Leroy K, Yilmaz Z, Brion JP (2007) Increased level of active GSK-3beta in Alzheimer's disease and accumulation in argyrophilic grains and in neurones at different stages of neurofibrillary degeneration. Neuropathol Appl Neurobiol 33(1):43-55

\section{Publisher's Note}

Springer Nature remains neutral with regard to jurisdictional claims in published maps and institutional affiliations.
Ready to submit your research? Choose BMC and benefit from:

- fast, convenient online submission

- thorough peer review by experienced researchers in your field

- rapid publication on acceptance

- support for research data, including large and complex data types

- gold Open Access which fosters wider collaboration and increased citations

- maximum visibility for your research: over $100 \mathrm{M}$ website views per year

At BMC, research is always in progress.

Learn more biomedcentral.com/submissions 